\title{
Article \\ Algebraization Levels in the Study of Probability
}

\author{
María Burgos *, Carmen Batanero (D) and Juan D. Godino
}

\author{
Department of Mathematics Education, University of Granada, 18071 Granada, Spain; batanero@ugr.es (C.B.); \\ jgodino@ugr.es (J.D.G.) \\ * Correspondence: mariaburgos@ugr.es
}

check for updates

Citation: Burgos, M.; Batanero, C.; Godino, J.D. Algebraization Levels in the Study of Probability. Mathematics 2022, 10, 91. https://doi.org/ $10.3390 /$ math10010091

Academic Editors: Laura Muñiz-Rodríguez and María Magdalena Gea Serrano

Received: 6 December 2021

Accepted: 23 December 2021

Published: 27 December 2021

Publisher's Note: MDPI stays neutral with regard to jurisdictional claims in published maps and institutional affiliations.

Copyright: (C) 2021 by the authors. Licensee MDPI, Basel, Switzerland. This article is an open access article distributed under the terms and conditions of the Creative Commons Attribution (CC BY) license (https:// creativecommons.org/licenses/by/ $4.0 /)$.

\begin{abstract}
The paper aims to analyze how the different degrees of mathematical formalization can be worked in the study of probability at non-university educational levels. The model of algebraization levels for mathematical practices based on the onto-semiotic approach is applied to identify the different objects and processes involved in the resolution of a selection of probabilistic problems. As a result, we describe the possible progression from arithmetic and proto-algebraic levels of mathematical activity to higher levels of algebraization and formalization in the study of probability. The method of analysis developed can help to establish connections between intuitive/informal and progressively more formal approaches in the study of mathematics.
\end{abstract}

Keywords: probability; formalization; fundamental stochastic ideas; algebraization levels

\section{Introduction}

Today we are witnessing a debate in statistics education regarding the possibility of teaching different contents, such as statistical inference to students with limited knowledge of algebra or calculus through informal approaches [1-3]. A similar discussion is observed in relation to other mathematical topics, for which the recommendation is a stronger emphasis on understanding and solving problems [4] while avoiding unnecessary formalizations as well as learning computational algorithms, which are less relevant because of technology.

In order to facilitate the understanding of the teaching contents, and according to students' previous knowledge, the study of mathematics can be carried out with different degrees of formalization, which depend on the generalization, symbolization, and analytical computation processes; in other words, these different levels are linked to the use of algebraic concepts and processes.

A contribution to this discussion is to admit the possibility of different formalization levels, i.e., various degrees of using algebra throughout the learning of mathematics. The view of algebra as the application of unknowns, equations, functions, parameters, or abstract structures, whose properties make it possible to operate with symbols, is restrictive since it conceals an essential feature of algebraic reasoning: that of generalization and progressive expression of generality. An extended view recognizes the presence of algebraic thinking even in the primary school mathematical activity $[5,6]$. In particular, the algebraic reasoning levels model $[7,8]$ systematizes and completes such an extended view and enables to clarify the levels of mathematical formalization in the study of whatever content.

In this paper, we center probability, because of the diversity of random situations that we have to face in our lives, and its necessity in the later study of inference. Due to this relevance, several curricular proposals $[9,10]$ introduce probability in Primary Education, pursuing to achieve the probabilistic literacy needed for every citizen [11].

The aim of this paper is to analyze the algebraic activity required in the work with probability at non-university levels and to describe it using the levels proposed in the algebraic reasoning model $[7,8]$. In this way, it is possible to define different degrees of formalization in the study of probability, depending on the algebraic reasoning level required in each of them, and to propose a sequence for introducing the fundamental ideas 
of probability at these educational stages. Furthermore, this study can also contribute to the discussion between the formal and informal teaching of probability and to the understanding of what is meant by formalization in the study of mathematics. This analysis helps define learning trajectories that take into account the connection between formal and informal mathematical work.

The organization of the paper is as follows. After this introduction, the theoretical framework and method are described. Next, a series of problems centered on the classical meaning of probability, which introduces the fundamental stochastic ideas with a progression of algebraization levels, are analyzed. The fourth section includes a synthesis of the fundamental stochastic ideas in relation to the algebraization levels and their suggested distribution for the different educational stages. Finally, we reflect on the relevance of the type of analysis performed in order to progress from the intuitive/informal to the formal component in mathematical learning.

\section{Theoretical Framework and Method}

In this section, we synthesize the following foundations of the work: some notions of the Onto-semiotic Approach (OSA) to mathematical knowledge and instruction [12-14], different meanings of probability and fundamental stochastic ideas, and finally the algebraic reasoning model.

\subsection{Pragmatic Meaning and Onto-Semiotic Configuration}

The OSA assumes an anthropological conception of mathematics, which gives a central place to the notion of mathematical practice, as "any action or expression (verbal, graphical, etc.) carried out by someone to solve mathematical problems, communicate the solution obtained to others, and validate or generalize it to different contexts and problems" [12], p. 334. Mathematics is also considered as a logically organized system of mathematical objects according to their nature and function in mathematical practices. These objects are classified into: problem-situations (tasks that induce mathematical activity); languages (terms and expressions, e.g., notations, symbols, graphical representations); concepts (mathematical entities that can be introduced by their definition); propositions (properties or statements about concepts); procedures (calculation techniques, operations, and algorithms), and; arguments (required to justify propositions or procedures).

These objects are related to one another creating onto-semiotic configurations. problemsituations are the raison d'être of mathematical activity; language constitutes the instrument of mathematical work and represents the other entities; arguments justify the procedures and propositions. In OSA, a distinction is made between extensive objects if they are involved in mathematical practice as a specific case, and intensive objects if appearing as a class or type of objects; these entities result from the corresponding mathematical processes of particularization and generalization, being relative to the situation under analysis.

\subsection{Pragmatic Meanings of Probability and Fundamental Stochastic Ideas}

Different interpretations of the concept of probability (intuitive, classical, frequentist, subjective, and axiomatic) have been proposed throughout history and are currently used in teaching [15,16], which have been interpreted within OSA as pragmatic meanings [17].

The intuitive meaning of probability emerged in ancient times in association with games of chance and religious rituals, in situations requiring the expression of personal degrees of belief about the occurrence of particular events and the qualitative assignment of probabilities.

The classical meaning started to develop in the 13th century [18], although the first mathematical definition was proposed by De Moivre in 1718 and refined by Laplace in 1814 as the ratio between the number of favorable cases to the number of possible cases, provided that all outcomes were equally probable [16]. This definition is circular and can only be applied in experiments with a finite number of equiprobable events. 
Bernoulli's demonstration of the first law of large numbers was the origin of the frequentist meaning of probability, in which probability is defined as the limit towards which the relative frequency of an event tends when repeating the experiment a large number of times. Although this definition extends the probability calculation to experiments with non-equiprobable events, it does not allow us to obtain the true value of the probability, but only an estimate of the same; moreover, it requires the independence of successive trials that should be performed under identical conditions [16,17].

By means of Bayes' theorem, the value of the (a priori) probability for an event could be revised on the basis of new data to transform it into an a posteriori probability. At the beginning of the 20th century, mathematicians such as Finetti or Ramsey relied on this theorem to define probability as a degree of belief based on personal experience [16]. With this, the field of application is broadened, but probability loses its objective character as it is conditioned by a given system of knowledge [19].

The controversy over the problems described for the various meanings of probability was resolved with the development of the axiomatic theory [19]. Starting from set theory, Kolmogorov defined probability as a measurable function that fulfilled some axioms and that allowed the development of all the results known at the time on probability calculation. These axioms are satisfied in the above definitions of probability and thus were accepted by the different statistical schools [17].

In addition to the idea of probability itself, Heitele [20] suggested that the mathematical study of probability requires consideration of specific fundamental stochastic ideas, which are frequently present in random situations and can be taught with different degrees of formalization. These ideas are:

- The set of all possibilities (sample space), the events, and their elementary operations (complementary, union, intersection).

- Equidistribution, which allows assigning probability for equiprobable events.

- The sum and product rules in the calculation of probabilities.

- Independence and dependence of events as well as conditional probability.

- Compound experiment, its sample space, conditional and compound probability.

- Elementary combinatorics is applied in the construction of the sample space and calculation of probabilities.

- Random variable, mathematical expectation, and distribution of the random variable.

- Convergence and law of large numbers.

- Sampling and estimation.

Consequently, the understanding of probability is achieved after a prolonged study process, which depends on the level of formalization, which should be adjusted to the type of students to whom it is directed. We will make operative this level of formalization by means of the Elementary Algebraic Reasoning (EAR) model.

\subsection{Algebraization Levels}

In the OSA framework, Elementary Algebraic Reasoning (EAR) is understood as the system of practices related to the resolution of tasks in which algebraic objects and processes are involved (symbolization, relationships, variables, unknowns, equations, patterns, generalization, modeling, etc.). The EAR model [7] employs as criteria to delimit the distinct levels of the types of objects, the generalization processes involved (or degree of intension), and the analytical calculation that is brought into play in the corresponding mathematical activity. Based on these, the following levels are defined:

- Level 0. Absence of algebraic reasoning. The person operates with intensive objects of first generality degree, using natural, numerical, iconic, and gestural languages.

- Level 1. The properties of operations and the relational meaning of the equal sign are recognized, and the concept of equivalence emerges. A general rule is identified in functional tasks.

- Level 2. Symbolic representations are used to represent intensive objects linked to contextual information; equations of the form $\mathrm{A} x+\mathrm{B}=\mathrm{C}(\mathrm{A}, \mathrm{B}, \mathrm{C} \in \mathbb{R})$ are solved. In 
functional tasks, a general rule is recognized, but operations with variables are not performed.

- Level 3. Established forms of algebraic reasoning appear. Symbols are used analytically, without reference to contextual information. Operations with indeterminates or variables are performed; equations of the type $A x+B=C x+D(A, B, C, D \in \mathbb{R})$ are solved.

Godino et al. [8] have proposed three new levels, resorting to the use and treatment of parameters, which are linked to families of equations and functions. The language used in these levels is symbolic and the symbols are managed analytically, without referring to contextual information.

- $\quad$ Level 4. Variable parameters and coefficients are used to specify families of equations and functions, implying discrimination of the domain and range of parametric functions. Operations with variable coefficients are implicated, but not with parameters.

- Level 5. This level describes the mathematical activity in which analytical (syntactic) computations involving parameters in conjunction with other variables are carried out.

- Level 6. The highest level of generality is the work with algebraic structures (such as vector space or group) or the function algebra (addition, subtraction, division, multiplication, and composition of generic functions), which are topics started in high school.

The algebraization levels are defined in terms of the objects and processes that are required and emerge in the mathematical activity carried out by a given subject when solving a specific task. They are not assigned to the tasks themselves, which can be solved in different ways, being able to bring into play a different algebraic activity, nor are they assigned to the individuals, who can develop solutions that involve objects or processes corresponding to different algebraization levels for the same problem-situation (The theory of algebrization levels developed in several articles by Godino and collaborators $[7,8]$ is not presented as a "theory of levels of cognitive development" of subjects, but has a local character, referring to the mathematical activity carried out in a specific task. This does not mean that it would not be possible to complete this theory with new criteria and instruments for assigning subjects a level of cognitive development in the algebra domain.) The study of the algebraization levels in probability tasks performed in this paper will allow teachers to become aware of their progressive degrees of epistemic and cognitive complexity, as well as to plan the study of this content in a suitable way.

\subsection{Method}

The characterization of the formalization levels in probability teaching, which can be used as a global reference for curriculum design, involves a macroscopic point of view that incorporates the background summarized in the previous sections. Furthermore, it also requires a microscopic analysis of prototypical examples of situations-problems, such as that proposed in Godino [21], in which the fundamental stochastic ideas and the different ways of addressing their resolution intervene in a critical way.

With this idea in mind, in the following section, we have selected and solved a number of problems that are graded according to the levels of Elementary Algebraic Reasoning (EAR) required in their resolution. To highlight these EAR levels, as well as the fundamental stochastic ideas involved in these problems, we perform a semiotic analysis of the practices that should be carried out to achieve the solution, and identify the concepts, procedures, propositions, and arguments used. All this enables us to define degrees of formalization in the study of probability and to establish hierarchical relationships between them according to their complexity and interdependence. 


\section{Algebraization Levels in Probabilistic Reasoning}

The teaching of probability should start from the children's intuitive ideas about chance and probability and culminate with the axiomatic approach, which introduces the work with algebraic structures. Following this principle, this section progressively introduces the algebraization levels for the study of probability, using examples of the classical meaning.

The first notions of probability are acquired through experience with situations that require the quantification of uncertain events or the expression of degrees of belief in them [22]. The assignment of probabilities to events is performed qualitatively, using everyday language ("not very likely", "very likely") based on individual preferences. In some cases, the probabilities are ordered by their highest plausibility ("more likely", "less likely") and are only quantified in simple cases ("there are 2 more than"). Mathematical procedures are not systematically used.

\subsection{Arithmetic Level}

Random Experiment, Sample Space, Events, Probability

Games of chance are a major context in which children can understand the characteristics of random situations by working out the classical meaning [15]. If a sample space, E consists of a finite number $n$ of elementary events and there is no reason to assume that any of them can happen more frequently than the remainder, then the probability of each elementary event is $1 / n$. Thus, applying Laplace's rule, the probability of an event composed of $k$ elementary events is equal to $k / n$.

In the EAR model, the arithmetic level is characterized by the implementation of arithmetic procedures of calculation on particular numbers and natural or numerical language. This level appears when solving the following prototypical problem of probability comparison (depending on the two urns' composition, the problem can be solved by strategies ranging from the comparison of favorable cases to the comparison of fractions [23]), which is analyzed in Table 1.

Table 1. Algebraic reasoning level 0 solution to Problem 1.

\begin{tabular}{cc}
\hline Mathematical Practices & Mathematical Objects \\
\hline $\begin{array}{c}\text { There are twice as many red marbles in } \\
\text { box A as blue marbles, and less than } \\
\text { twice as many in box B. Therefore, in } \\
\text { box B the probability of drawing a blue } \\
\text { marble is higher. }\end{array}$ & $\begin{array}{c}\text { Concepts: experiment, events, favorable and } \\
\text { Procedures: distinguishing and counting favorable } \\
\text { and possible cases, computing the ratio of favorable } \\
\text { and possible cases; comparing ratios. }\end{array}$ \\
& $\begin{array}{c}\text { Propositions: Events are equiprobable, the probability } \\
\text { of occurrence for an event depends on the ratio of } \\
\text { favorable to unfavorable cases. }\end{array}$ \\
\hline
\end{tabular}

Problem 1. There are 4 red marbles and 2 blue marbles in box A. Box B contains 6 red marbles and 4 blue marbles (Figure 1). To win a prize, one must remove a blue marble from the box without looking inside it. Which box would you choose to make the extraction?

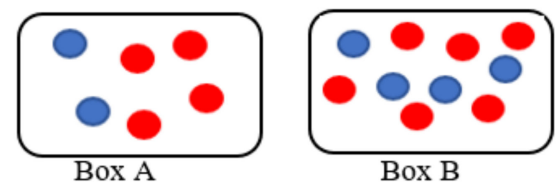

Figure 1. Boxes composition in Problem 1.

In the practices analyzed in Table 1, only particular numerical values (number of red and blue marbles in the boxes), arithmetic operations (doubling a quantity), and order of natural numbers intervene. The established correspondence strategy [23] leads 
to computing the ratio in one box ("twice as many red marbles as blue marbles") and comparing it with the same ratio in the other box. Since neither algebraic objects nor algebraic processes are involved, the mathematical activity performed is classified as algebraization level 0, according to Godino et al. [7].

\subsection{Proto-Algebraic Level}

When similar to Problem 1, neither the number of favorable nor the number of unfavorable cases coincide, the probability comparison problem cannot be solved by comparing these values, so that proportional reasoning must be applied (proportional reasoning appears when solving situations that are characterized by two types of relationships (a) functional relationships that link different magnitudes and reflect the meaning of ratio, and (b) scalar relationships that link quantities of the same magnitude [24]). In Problem 1 , we can compare the ratio between the quantities "number of blue marbles" (favorable cases) and "number of red marbles" (unfavorable cases), or between "number of blue marbles" (favorable cases) and "number of marbles in the box" (possible cases). Another solution to this problem is using Laplace's rule to determine the probability of success in each box in order to choose the one with the highest probability. Such a strategy, which is analyzed in Table 2, and is based on the comparison of the fractions determined by the favorable and possible cases, implies a proto-algebraic level 1 mathematical activity, since intensive objects of second degree of generality (rational numbers), properties of the algebraic structure of $\mathbb{N}$ and equality as equivalence intervene.

Table 2. Algebraic reasoning level 1 solution to Problem 1.

\begin{tabular}{|c|c|}
\hline Mathematical Practices & Mathematical Objects \\
\hline & $\begin{array}{c}\text { Concepts: chance, chance games, favorable and } \\
\text { unfavorable cases, probability }\end{array}$ \\
\hline $\begin{array}{l}\text { Since there are two blue marbles and four red } \\
\text { marbles in box A, the probability of getting a } \\
\text { blue marble is } 2 / 6 \text {. Similarly, there are } 4 \text { blue }\end{array}$ & $\begin{array}{l}\text { Procedures: distinguishing and counting } \\
\text { favorable and possible cases, applying } \\
\text { Laplace's rule, comparing fractions. }\end{array}$ \\
\hline $\begin{array}{l}\text { and } 6 \text { red marbles in box } B \text {, so that the } \\
\text { probability of getting a blue marble in box } B \text { is }\end{array}$ & $\begin{array}{l}\text { Propositions: Events are equiprobable, the } \\
\text { probability of occurrence for an event depends }\end{array}$ \\
\hline $4 / 10$. Then, the probability of drawing a blue & on the number of elements; a fraction is smaller \\
\hline $\begin{array}{c}\text { marble in box } \mathrm{B} \text { is } 4 / 10 . \text { Now, } 2 \times 10=20<24 \\
=6 \times 4 \text {, and hence, } 2 / 6<4 / 10 \text {. }\end{array}$ & $\begin{array}{l}\text { than another if the product of its numerator by } \\
\text { the denominator of the second fraction is }\end{array}$ \\
\hline Thus, the probability of success is lower for box & smaller than the product of its denominator by \\
\hline A than box B. & the numerator of the second fraction. \\
\hline & $\begin{array}{l}\text { Arguments: based on equiprobability of events, } \\
\text { Laplace's rule, and properties of fractions. }\end{array}$ \\
\hline
\end{tabular}

\subsubsection{Compound Experiment, Compound Probability}

In secondary school, we introduce compound experiments, whose handling implies a higher complexity, since they involve combinatorial principles in the enumeration of the sample space. In urn problems, a distinction is made between sampling with or without replacement, which entails the independence or dependence of simple experiments, as we see in Problem 2.

Problem 2. There are two blue balls and four red balls in a box. Two balls are drawn one after another, noting the color of the first ball and returning it to the urn, before drawing the second one. What is the probability of obtaining two blue balls? What happens if both balls are drawn simultaneously from the urn?

In the practices included in Table 3, properties and calculation with fractions and equality as equivalence are involved, so that the mathematical activity has a proto-algebraic level 1 character. The product rule enables the solution of compound probability problems 
if the experiments are independent. In dependent experiments, we generalize by making use of conditional probability.

Table 3. Algebraic reasoning level 1 solution to Problem 2.

\begin{tabular}{|c|c|}
\hline Mathematical Practices & Mathematical Objects \\
\hline $\begin{array}{l}\text { We are dealing with a compound experiment. } \\
\text { In the first part, a sampling with replacement is } \\
\text { performed, with the result of the second } \\
\text { extraction being independent of the first. Since } \\
\text { there are two blue marbles and four red } \\
\text { marbles in the box, the probability of obtaining } \\
\text { a blue marble is } \frac{2}{6}=\frac{1}{3} ; P(1 \text { st blue ball })=\frac{1}{3} \text {; } \\
\qquad P(2 \text { d blue ball })=\frac{1}{3} \text {; } \\
\text { Therefore, the probability that the two balls are } \\
\text { blue is } P(2 \text { blue balls })=\frac{1}{3} \times \frac{1}{3}=\frac{1}{9} \text {. } \\
\text { The second experiment depends on the first } \\
\text { one and the probability of obtaining the blue } \\
\text { ball is modified. As } P(2 n d \text { ball blue })=\frac{1}{5} \text { then } \\
P(2 \text { blue balls })=\frac{1}{3} \times \frac{1}{5}=\frac{1}{15}\end{array}$ & $\begin{array}{c}\text { Concepts: Experiment. Favorable and possible } \\
\text { cases. Compound experiment, compound } \\
\text { probability, independence, dependence, } \\
\text { conditional probability, sampling with and } \\
\text { without replacement. } \\
\text { Procedures: calculation of simple and } \\
\text { compound probabilities. Product of fractions. } \\
\text { Propositions: Sampling with replacement } \\
\text { assumes independence of trials. }\end{array}$ \\
\hline
\end{tabular}

\subsubsection{Random Variable, Fair Game, Expectation}

In a compound experiment, the cartesian product of the sample spaces of the simple experiments gives the sample space. As an example, let us consider the following problem in which, in addition, the ideas of a random variable, distribution, and mathematical expectation are implicit:

Problem 3. We roll two dice and add up the scores. What score would you bet on to have the best chance of winning?

The description of the sample space associated appears in Table 4.

Table 4. Sample space corresponding to Problem 3.

\begin{tabular}{ccccccc}
\hline & \multicolumn{7}{c}{ Dice 2 } \\
\hline Dice 1 & $\mathbf{1}$ & $\mathbf{2}$ & $\mathbf{3}$ & $\mathbf{4}$ & $\mathbf{5}$ & $\mathbf{6}$ \\
\hline 1 & $(1,1)$ & $(1,2)$ & $(1,3)$ & $(1,4)$ & $(1,5)$ & $(1,6)$ \\
2 & $(2,1)$ & $(2,2)$ & $(2,3)$ & $(2,4)$ & $(2,5)$ & $(2,6)$ \\
3 & $(3,1)$ & $(3,2)$ & $(3,3)$ & $(3,4)$ & $(3,5)$ & $(3,6)$ \\
4 & $(4,1)$ & $(4,2)$ & $(4,3)$ & $(4,4)$ & $(4,5)$ & $(4,6)$ \\
5 & $(5,1)$ & $(5,2)$ & $(5,3)$ & $(5,4)$ & $(5,5)$ & $(5,6)$ \\
6 & $(6,1)$ & $(6,2)$ & $(6,3)$ & $(6,4)$ & $(6,5)$ & $(6,6)$ \\
\hline
\end{tabular}

This two-way table (Table 4) requires a representation/interpretation process of a higher level of generality (set of numbers pairs, classified in rows and columns). From this table, we determine the sum of pairs and the probability distribution of the variable "sum of two dice". Three different objects correspond to each value of the var-iable "sum of two dice" in Table 5: in the second column, the possible outcomes of the experiment are assigned; in the third column are the number of favorable cases, and, in the fourth column, the probability of obtaining each variable value. 
Table 5. Probability distribution for the sum of two dice. Algebraic level 2.

\begin{tabular}{cccc}
\hline Sum & Posible Casess & Favourable Cases & Probability \\
\hline 2 & $(1,1)$ & 1 & $1 / 36$ \\
3 & $(1,2),(2,1)$ & 2 & $2 / 36$ \\
4 & $(1,3),(2,2),(3,1)$ & 3 & $3 / 36$ \\
5 & $(1,4),(2,3),(3,2),(4,1)$ & 4 & $4 / 36$ \\
6 & $(1,5),(2,4),(3,3),(4,2),(5,1)$ & 5 & $5 / 36$ \\
7 & $(1,6),(2,5),(3,4),(4,3),(5,2),(6,1)$ & 6 & $6 / 36$ \\
8 & $(2,6),(3,5)(4,4),(5,3),(6,2)$ & 5 & $5 / 36$ \\
9 & $(3,6),(4,5),(5,4),(6,3)$ & 4 & $4 / 36$ \\
10 & $(4,6),(5,5),(6,4)$ & 3 & $3 / 36$ \\
11 & $(5,6),(6,5)$ & 2 & $2 / 36$ \\
12 & $(6,6)$ & 1 & $1 / 36$ \\
\hline Total & & 36 & \\
\hline
\end{tabular}

A probability table serves as an icon for these relationships structure and allows us to gain knowledge about the probability distribution's characteristics and shape. Thus, we observe that the mode of the variable is 7 , therefore, we should bet on 7 , since its probability of $6 / 36$ is the highest. This functional aspect, and not using alphanumeric symbols which are characteristic of consolidated algebraic reasoning (level 3), lead to assigning proto-algebraic level 2 to the mathematical activity involved in the solution.

As we mentioned before, the probability is raised from situations linked to games of chance. In these problems, a random variable that takes at least two different values (the profit assigned to each player if he/she wins) is implicitly considered. This set of values with their probabilities constitutes the probability distribution of the random variable, whose mean is known as the mathematical expectation. For a fair game, it will be necessary to equalize the winning expectations, i.e., the products of the prize awarded and the probability of winning for each player. Thus, the first step in deciding whether a game is fair is to compare the winning probabilities of the different players. This is the context of Problem 4.

Problem 4. Alice and Paul are playing a game using a box with marbles. Alice has 4 red marbles and 2 blue marbles in her box. Pablo keeps in his box 6 red marbles and 4 blue marbles. Paul wins 50 cents each time he draws a red marble. How much should Alice win each time she draws a blue marble to make the game fair?

In Problem 4, the ideas of a random variable and mathematical expectation appear implicitly. As shown in Table 6, the solution requires both computing the probabilities of success by each player and recognizing the inverse proportionality relationship between the winning expectation and the amount received. This means posing and solving an equation in which the unknown (winnings of a player) is cleared in one member of the equation. Thus, according to Godino et al. [7], a proto-algebraic activity of algebraization level 2 is developed. 
Table 6. Algebraic reasoning level 2 solution to Problem 4.

\begin{tabular}{|c|c|}
\hline Mathematical Practices & Mathematical Objects \\
\hline $\begin{array}{l}\text { As Alice wins whenever she draws a blue marble } \\
\text { and Paul wins whenever he draws a red marble, } \\
\text { the probabilities of each of them winning are: } \\
\qquad P\left(\text { "Alice wins") }=\frac{2}{6}=\frac{1}{3} \text {; }\right. \\
\qquad P(\text { "Paul wins") })=\frac{6}{10}=\frac{2}{5} \\
\text { If } x \text { is the amount Alice must win when she gets } \\
\text { the blue marble, and Paul wins } 50 \text { cents when it is } \\
\text { red, for the game to be fair, it must follow that } \\
P(\text { "Alice wins") } \times x=P(\text { "Paul wins") } \times 50 \\
\text { That is, } \frac{1}{3} x=\frac{2}{5} \times 50 \text {, where } \frac{1}{3} x=20 \text {, and so } x=60 . \\
\text { That is, Alice must earn } 60 \text { cents each time the } \\
\text { marble is blue. }\end{array}$ & $\begin{array}{l}\text { Concepts: chance, fair play, favorable and } \\
\text { possible cases, probability, random variable, } \\
\text { mathematical expectation. } \\
\text { Procedures: calculation of probabilities, } \\
\text { equalization of expected winnings of the } \\
\text { players, formulation, and resolution of the } \\
\text { inverse proportionality equation. } \\
\text { Propositions: Profits and probabilities are } \\
\text { inversely proportional. } \\
\text { Arguments: The game is fair if the players } \\
\text { have the same expected profit. }\end{array}$ \\
\hline
\end{tabular}

\subsection{Algebraic Level}

The assignment of a strictly algebraic level (level 3) to a practice requires the use of symbolic-literal language and an analytical/syntactic operation with such language [7]. To exemplify this, Problem 5 is analyzed.

Problem 5. There are 4 red marbles and 2 blue marbles in box A. In box B there are 6 red marbles and 4 blue marbles (Figure 1). How would you distribute 8 red marbles so that the probability of getting a blue marble is the same in both boxes?

In an arithmetic solution, we could reason as follows: We can distribute the 8 red marbles, by placing 2 in box A to make 6 red marbles, and 6 in box B resulting in 12 red marbles. In this way, there would be three times as many red marbles as blue marbles in both boxes and, therefore, there would be an equal probability of drawing blue marbles. Another solution with a higher algebraization level that permits generalizing the result to other compositions of favorable and possible cases in the boxes is provided in Table 7.

Table 7. Algebraic reasoning level 3 solution to Problem 5.

\begin{tabular}{|c|c|}
\hline Mathematical Practices & Mathematical Objects \\
\hline $\begin{array}{l}\text { Let } a \text { be the number of red marbles that are } \\
\text { placed in box A, and } b \text { the number that is } \\
\text { added to box B. To have the same probability of } \\
\text { drawing a blue marble, the following must } \\
\text { be satisfied: } \\
\qquad \frac{2}{2+4+a}=\frac{4}{4+6+b} \Rightarrow \\
\begin{array}{r}2(10+b)=4(6+a) \Leftrightarrow 20+2 b=24+4 a \\
\Leftrightarrow 2 b=4+4 a \Leftrightarrow b=2+2 a\end{array} \\
\text { Since the number of marbles to be distributed } \\
\text { is } 8, a+b=8 ; b=8-a \text {. So, } \\
8-a=2+2 a \Leftrightarrow 6=3 a \Leftrightarrow a=2 \\
\text { Hence, we should add } 2 \text { red marbles to box A } \\
\text { and the remaining marbles to box B. }\end{array}$ & $\begin{array}{c}\text { Concepts: experiment, favorable and possible } \\
\text { cases, probability, ratio, } \\
\text { Procedures: applying Laplace's rule, posing a } \\
\text { system of equations, and substituting to solve } \\
\text { the equation } \mathrm{A} x+\mathrm{B}=\mathrm{C} x+\mathrm{D} \text {. } \\
\text { Propositions: The red marbles (unfavorable } \\
\text { cases) should be distributed so that the number } \\
\text { of blue marbles is directly proportional to the } \\
\text { number of total marbles. } \\
\text { Arguments: Based on the definition of } \\
\text { probability and the proportionality } \\
\text { relationship. }\end{array}$ \\
\hline
\end{tabular}

Here, the equations have been posed symbolically and a substitution technique is applied to solve them; therefore, the reasoning corresponds with an algebraization level 3, according to the EAR model [7].

\subsection{Meeting Parameters for the Fist Time}

In probability, it is characteristic to use general distributions that are determined by one or several parameters, such as the binomial distribution $B(n, p)$, which is studied in high school. Given a random experiment and an event $A$, with probability $p$, we say that there is 
success if the experiment results in $A$, otherwise we speak of it as failure. In $n$ independent repetitions of the experiment, the number of successes is a random variable $X$, with integer values between 0 and $n$, which follows a binomial distribution of parameters $n$ (number of trials) and $p$ (probability of success in each one). This is the context of Problem 6.

Problem 6. Consider the experiment consisting of rolling two dice and adding their scores. What is the probability of getting the sum 7 a given number of times in $n$ repetitions of the experiment?

This first approach to parameters in determining the probability of success in $k$ trials of the $n$ repetitions, described in Table 8 , is a level 4 in the EAR model [8].

Table 8. Algebraic reasoning level 4 solution to Problem 6.

\begin{tabular}{|c|c|}
\hline Mathematical Practices & Mathematical Objects \\
\hline 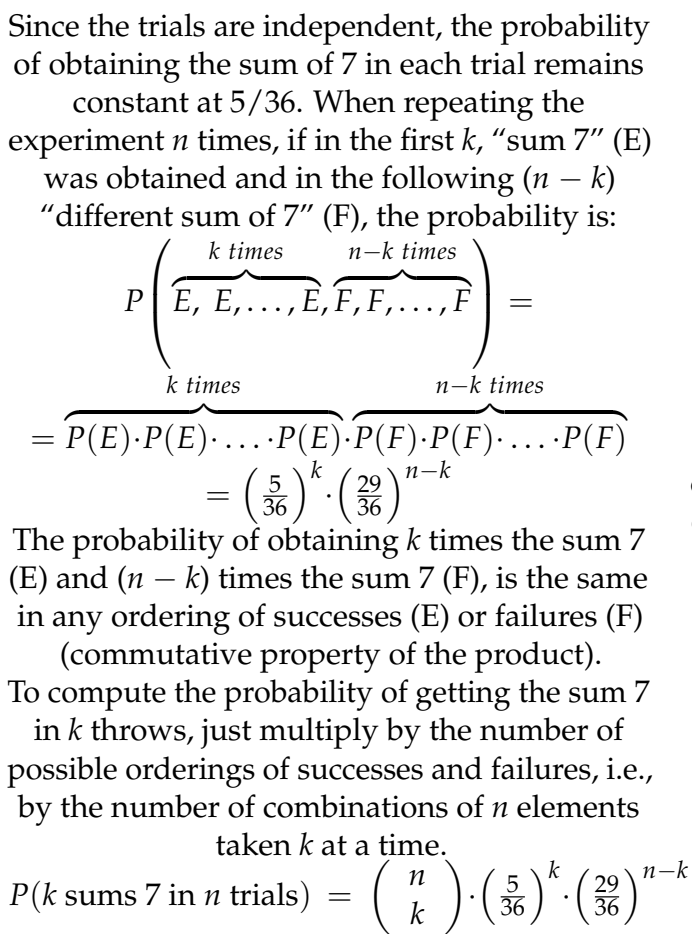 & 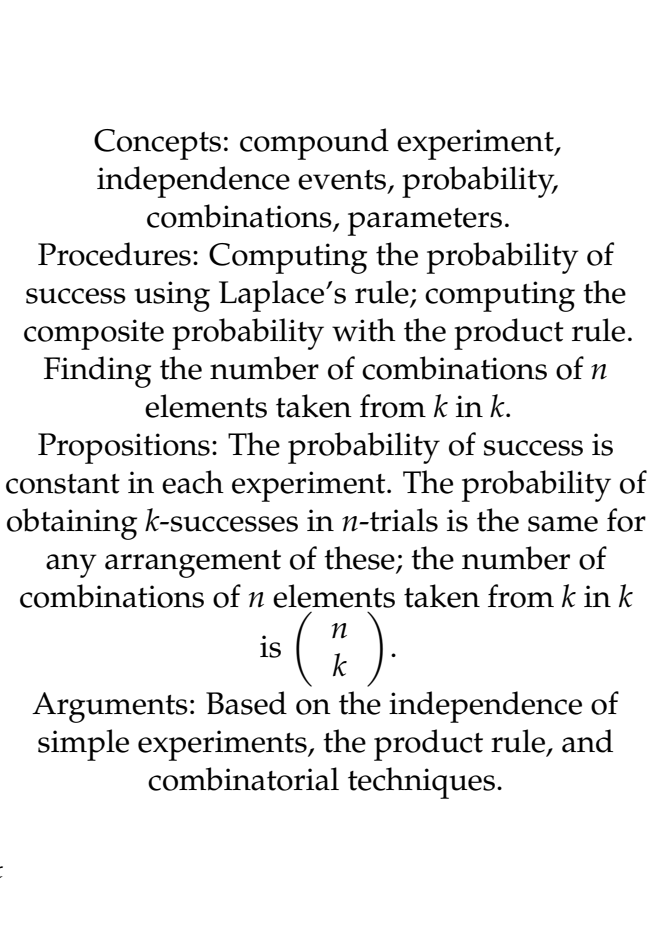 \\
\hline
\end{tabular}

The use of parameters encourages the reification of formulas and algebraic expressions, and it is a way of generalization by determining families of objects (probability distributions, in our case) that can be modeled and represented by a common structure [25].

In particular, the situation described in Problem 6 can be generalized to a binomial distribution $B(n, p)$ of parameters $n$ and $p$, whose probability distribution is:

$$
P(X=k)=\left(\begin{array}{c}
n \\
k
\end{array}\right) p^{k}(1-p)^{n-k} k=1, \ldots n .
$$

\subsection{Operations with Parameters}

Computational operations with parameters appear in high school textbooks in the study of normal distribution and statistical inference. Once continuous random variables and the concepts of density function and distribution have been covered, the normal distribution of parameters $\mu$ and $\sigma, N(\mu, \sigma)$ is introduced, which is a continuous random variable with a density function: 


$$
f(x)=\frac{1}{\sigma \sqrt{2 \pi}} e^{-\frac{(x-\mu)^{2}}{2 \sigma^{2}}}, \text { for each } x \in \mathbb{R} .
$$

This distribution is studied, among other reasons, because of its applications in biological and psychological phenomena or in error theory. The distribution function of a continuous random variable $X$ is a real-variable function given by an integral:

$$
F(x)=P((-\infty \leq X \leq x])=\int_{-\infty}^{x} f(x) d x
$$

(In fact it is an improper integral not studied in high school.)

From it, probabilities of the variable in intervals are computed:

$$
P(a \leq X \leq b)=F(b)-F(a)=\int_{a}^{b} f(x) d x
$$

However, since the normal density function lacks a primitive, its distribution function has no explicit expression, and so numerical methods are used to obtain its values. In practice, students can either use a calculator that provides the values of the distribution function $F(x)$ given $x$, or a statistical table of the normal distribution $N(0,1)$. This requires employing the properties of the normal distribution to conclude that if $X$ is a normal variable $N(\mu, \sigma)$, then $Z=\frac{X-\mu}{\sigma}$ is a normal variable $N(0,1)$.

Problem 7. Determine in terms of $\mu$ and $\sigma$, the $90 \%$ percentile in a normal distribution $N(\mu, \sigma)$.

Obtaining the percentile in a normal distribution $N(\mu, \sigma)$ as proposed in Problem 7, requires operating with the parameters (Table 9 ) which are characteristic of the algebraization level 5 [8].

Table 9. Algebraic reasoning level 5 solution to Problem 7 .

\begin{tabular}{cc}
\hline Mathematical Practices & Mathematical Objects \\
\hline The 90 percentile is the value $P_{90}$ such as: & $\begin{array}{c}\text { Concepts: random variable, density function, } \\
\text { normal distribution, percentile, standard normal } \\
\text { distribution. }\end{array}$ \\
$P\left(X \leq P_{90}\right)=0.9$ & $\begin{array}{c}\text { Procedures: operations with parameters, using } \\
\text { th the normal } N(0,1) \text { table we observe: }\end{array}$ \\
$P(Z \leq 1.28)=0.9$ & $\begin{array}{c}\text { the } 1) \text { table, typification, and } \\
\text { inverse operation }\end{array}$ \\
where $Z=\frac{X-\mu}{\sigma}$. Then & $\begin{array}{c}\text { Propositions: Any linear combination of a } \\
P\left(\frac{X-\mu}{\sigma} \leq 1.28\right)=0.9 P\end{array}$ \\
then $P_{90}=\mu+1.28 \sigma$. & $\begin{array}{c}\text { normal random variable is also a normal random } \\
\text { variable. Typifying the normal distribution leads } \\
\text { to the } N(0,1) .\end{array}$ \\
& $\begin{array}{c}\text { Arguments: Based on the properties of the } \\
\text { normal distribution and the calculus of } \\
\text { probabilities. }\end{array}$ \\
\hline
\end{tabular}

This algebraization level 5 also appears in the approximation of the binomial distribution by a normal distribution. Thus, the De Moivre-Laplace Theorem ensures that the probability that the binomial distribution $B(n, p)$ converges to a normal distribution $N(n p, \sqrt{n p(1-p)})$ can be higher than a certain value, for a sufficiently high $n$, a good approximation being accepted when $n p \geq 5$ and $n(1-p) \geq 5$. (The theorem's complexity arises from the fact that it involves a succession of distributions $(B(n, p)$, with $n$ varying, whose limit is not an ordinary functional limit, but a stochastic convergence).

\subsection{Working with Algebraic Structures}

Although the problems discussed so far can be solved by means of the classical meaning of probability, in this section we will discuss other problems that are included in the axiomatic meaning. Since this meaning encompasses all the previous ones, this section 
can be considered an extension of the study of classical probability to a higher level of abstraction.

Kolmogorov proposed a satisfying axiomatic for probability, considering that the sample space associated with a random experiment is determined by the set $\Omega$ of all possible outcomes associated with the experiment (sample points) and a $\sigma$-algebra of events A over that sample space (i.e., a class of subsets of $\Omega$ closed for numerable unions, contrary and containing the empty set). He defined probability as a function of sets P: A $\rightarrow$ $\mathbb{R}$ satisfying three axioms:

$P 1$ (Non-negativity) $P(A) \geq 0$, for every $A \in \mathrm{A}$.

$P 2$ (Certain event) $P(\Omega)=1$.

$P 3$ ( $\sigma$-additivity) For every sequence $\left\{A_{i}\right\}$ of mutually incompatible events, $A_{i} \cap A_{j}=$ $\varnothing$, for every $i \neq j, P\left(\bigcup_{i=1}^{\infty} A_{i}\right)=\sum_{i=1}^{\infty} P\left(A_{i}\right)$.

These axioms allow to deduce the rules of probability calculation, but not the way to assign a probability to non-equiprobable elementary events [15]. However, in a random experiment with a finite sample space $\Omega$, assuming that all elementary events are equiprobable, the function $\mathrm{P}: \mathrm{P}(\Omega) \rightarrow \mathbb{R}$ is defined by

$P(A)=\# A$ (\#A denotes the cardinal of event $A$ ), fulfilling the previous axioms. This leads to the Laplace rule for the assignment of classical probabilities.

Less formally, Kolmogorov's axiomatics is introduced in high school and probability is defined in some texts as an application of each event in the interval [0,1]. Some properties that facilitate the resolution of problems when the probability of specific events in a sample space is known and the probability of others in the same space is to be determined are derived from the axioms. The proof of these propositions requires students to activate interpretation, unitarization, materialization, reification, and representation processes with intensive objects so that the degree of abstraction is higher than necessary in their application. Problem 8 discusses an example of an activity taken from a high school textbook.

Problem 8. Let $A$ and $B$ be two events. Consider the event $C$ : "only happens to one of them". Prove that $\mathrm{P}(\mathrm{C})=\mathrm{P}(\mathrm{A})+\mathrm{P}(\mathrm{B})-2 \mathrm{P}(\mathrm{A} \cap \mathrm{B})[26]$, p. 360 .

Table 10 shows that in order to solve Problem 8, the event $C$ "only one of the two occurs" must be interpreted by operations on the events A and B, so that "A occurs and B does not occur" is given by $A \cap \bar{B}$ and "B occurs and A does not occur" is $\bar{A} \cap B$. In this sequence of practices, events are seen as unspecific sets of a particular space, as abstract objects in which operations are defined (union, intersection, opposite) that fulfill a system of specific properties; probability is an application that is defined on such sets that fulfill certain "rules" in relation to their operations. Therefore, the algebraization level is 6.

Table 10. Algebraic reasoning level 6 solution to Problem 8.

\begin{tabular}{cc}
\hline Mathematical Practices & Mathematical Objects \\
\hline Considering $C=(A \cap \bar{B}) \cup(\bar{A} \cap B)$, & Concepts: sets, union, intersection, \\
$A=(A \cap B) \cup(A \cap \bar{B})$ and & complementary, disjoint sets. \\
$B=(A \cap B) \cup(\bar{A} \cap B)$, & Procedures: Operations with sets; operations \\
Using the additive property of probability; & with the probability function. \\
$P(C)=P(A \cap \bar{B})+P(\bar{A} \cap B)$, & Propositions: The union of an event and its \\
$P(A)=P(A \cap B)+P(A \cap \bar{B})$, & complementary is the sample space. The \\
$P(B)=P(A \cap B)+P(\bar{A} \cap B)$, & intersection of an event and the \\
Then: $P(C)=P(A \cap \bar{B})+P(\bar{A} \cap B)$ & complementary of another is equal to the \\
$=(P(A)-P(A \cap B))+(P(B)-P(A \cap B))$ & difference between the first and the second. \\
$=P(A)+P(B)-2 P(A \cap B)$. & Probability is additive in disjoint events. \\
\hline
\end{tabular}




\section{Synthesis and Articulation of Algebraization Levels in the Study of Probability}

Table 11 presents a summary of the fundamental stochastic ideas, algebraic objects, and algebraization levels that appear in the problems analyzed. We observe that the same stochastic ideas can be worked with the different algebraic reasoning degrees when choosing appropriately the type of problem and method of resolution.

Table 11. Synthesis of stochastic ideas and algebraic levels in the examples.

\begin{tabular}{|c|c|c|c|c|c|c|c|c|c|}
\hline \multirow{2}{*}{\multicolumn{2}{|c|}{ Stochastic Fundamental Ideas }} & \multicolumn{8}{|c|}{ Problem Examples } \\
\hline & & P1 & P2 & P3 & $\mathbf{P 4}$ & P5 & P6 & P7 & P8 \\
\hline \multirow{2}{*}{\multicolumn{2}{|c|}{$\begin{array}{c}\text { Probability, favorable, unfavorable and possible cases } \\
\text { Random experiment, sample space, event }\end{array}$}} & $x$ & $x$ & $\mathrm{x}$ & $\mathrm{x}$ & $x$ & $\mathrm{x}$ & $\mathrm{x}$ & $\mathrm{x}$ \\
\hline & & $x$ & $\mathrm{x}$ & $\mathrm{x}$ & $\mathrm{x}$ & $\mathrm{x}$ & $\mathrm{x}$ & $\mathrm{x}$ & $\mathrm{x}$ \\
\hline \multicolumn{2}{|c|}{ Equidistribution, equiprobability, Laplace rule } & $\mathrm{x}$ & $\mathrm{x}$ & $\mathrm{x}$ & $x$ & $x$ & & & \\
\hline \multicolumn{2}{|c|}{ Addition rule } & $x$ & $x$ & $x$ & $x$ & $x$ & $\mathrm{x}$ & $\mathrm{x}$ & $x$ \\
\hline \multicolumn{2}{|c|}{ Dependence and independence } & & $x$ & $x$ & & & & & \\
\hline \multicolumn{2}{|c|}{ Compound experiment, joint probability } & & $x$ & $x$ & & & $\mathrm{x}$ & & \\
\hline \multirow{2}{*}{\multicolumn{2}{|c|}{ Random variable, distribution, expectation }} & & $x$ & $x$ & & & $x$ & & \\
\hline & & & & $x$ & $x$ & & $\mathrm{x}$ & $x$ & \\
\hline \multicolumn{2}{|c|}{ Sampling } & $\mathrm{x}$ & $\mathrm{x}$ & & & & & & \\
\hline \multicolumn{10}{|c|}{ Algebraic objects } \\
\hline \multicolumn{2}{|c|}{ Numerical sets } & $x$ & $\mathrm{x}$ & $\mathrm{x}$ & $\mathrm{x}$ & $x$ & & & \\
\hline \multicolumn{2}{|c|}{ Ratio, proportion } & $x$ & $x$ & $x$ & $x$ & $x$ & & & \\
\hline \multicolumn{2}{|c|}{ Alphanumerical symbols, equations } & & & $x$ & $x$ & $x$ & $\mathrm{x}$ & $x$ & $x$ \\
\hline \multicolumn{2}{|c|}{ Functions (distribution), representation } & & & $x$ & $x$ & & $\mathrm{x}$ & $x$ & \\
\hline \multicolumn{2}{|c|}{ Parameters } & & & & & & $\mathrm{x}$ & $\mathrm{x}$ & \\
\hline \multicolumn{2}{|c|}{ Operation with parameters } & & & & & & & $\mathrm{x}$ & \\
\hline \multicolumn{2}{|c|}{ Algebraic structures } & & & & & & & & $\mathrm{x}$ \\
\hline \multicolumn{10}{|c|}{ Algebraization levels } \\
\hline Arithmetic & 0 & $x$ & & & & $x$ & & & \\
\hline \multirow{2}{*}{ Protoalgebraic } & 1 & $x$ & $x$ & & & & & & \\
\hline & 2 & & & $x$ & $x$ & & & & \\
\hline \multirow{4}{*}{ Algebraic } & 3 & & & & & $x$ & & & \\
\hline & 4 & & & & & & $x$ & & \\
\hline & 5 & & & & & & & $x$ & \\
\hline & 6 & & & & & & & & $x$ \\
\hline
\end{tabular}

This observation corroborates two assumptions of Heitele [20]: (a) The fundamental ideas appear in the majority of random situations; (b) It is possible to teach them with different degrees of formalization. In this sense, this research work also complements that of Heitele [20] by operationalizing its degrees of formalization through the six levels proposed in the algebraic reasoning levels model.

Although not all of the particular problems chosen always contain all the stochastic ideas, it is possible to vary most of them, to make them implicit, and also to change the problem to work at a different algebraization level. So, for example, in Problem 2 one can assume that $n$ balls are drawn with replacement and ask for the probability of getting a number $x$ in red, which would lead to the random variable, (binomial) distribution, and use of parameters (level 4).

This analysis also enables us to reflect on the algebraic reasoning levels implicit in working with probability in the curriculum $[10,27]$. In Primary Education, students begin to work intuitively and at an arithmetical level, in order to bring them closer to the random phenomena of their daily lives and expand their probabilistic language. Later they reach the calculation of probability as a quotient of favorable and possible cases in simple problems. By the end of this phase, students have worked on ratios and proportionality, which are closely related to some probabilistic content [28,29]. 
Once Compulsory Secondary Education (CSE; $12-16$ year-olds) begins, students are expected to be able to make sense of the notions of ratio and proportion in proportional and inversely proportional magnitudes [30], which would allow them to work on fair games in which players have different probabilities of winning. The problems on compound experiments that are introduced in 3rd grade (14-15 year-olds) can be initially based on the tree diagram (one of the main tools in probability and combinatorics, according to Fischbein, [31]). By the end of secondary education, the formal study of combinatorics is included, in which calculation formulae parameters are involved, which implies algebraization level 4.

Although the probability axioms can be discussed intuitively, their formal expression on the basis of Kolmogorov's theory at algebraization level 6 is currently only worked on in high school (17-18 year-olds) and their study is very limited, by giving preference to work with extra-mathematical situations. In the same way, although random variables and probability distributions appear implicitly in CSE in the mathematical activity characteristic of proto or algebraic levels, the study of distribution models, such as the binomial or normal distribution in which algebraization levels 4 and 5 are applied, is reserved for high school.

\section{Final Reflections}

The algebraic reasoning model applied in this article helps to deepen the characterization of mathematics proposed by other authors, from the epistemological and learning processes points of view. Thus, Fischbein [32] considers mathematics: “(a) as a formal, deductive and rigorous body of knowledge, as presented in advanced textbooks; (b) mathematics as a human activity" (p. 231). He also suggests recognizing the interactions between the formal, algorithmic, and intuitive components of mathematics.

Freudenthal [33] considers that mathematics should not be learned as a closed system but as an activity of mathematizing reality. Realistic Mathematics Education, developed on his ideas, distinguishes between horizontal and vertical mathematization. In the former, students use mathematical tools to organize and solve real-life problems, which involve moving from the real world to the world of symbols. Vertical mathematics involves the reorganization of symbols, connecting concepts and strategies within the mathematical system.

As we have demonstrated in this paper, OSA-based analysis of problem-solving reveals the presence of objects and processes characteristic of proto-algebraic levels, the recognition of which can help in the transition between intuitive, algorithmic, and formal components [32] and of the interactions between the horizontal and vertical component of mathematical activity [33]. Moreover, even within the formal study of mathematics, it is possible and useful to admit different degrees of generalization and formalization.

This research work could be continued by analyzing the algebraic reasoning levels in activities involving the frequentist and subjective meanings of probability, not considered here due to space limitations, or for other curricular contents. The implications of this type of analysis for teacher training should also be studied. The different degrees of formalization in probabilistic reasoning should be taken into account in the training of teachers to teach probability and in instruments for the evaluation of such knowledge, such as the one developed by [34].

The examples described will help the teacher to analyze the degree of generality and formalization in the mathematical activity involved in solving probability problems and planning instructional processes. This analysis can serve for evaluating at what educational stage and in what way the study of probability can be approached with different algebraization levels, whilst also taking into account the probabilistic contents that are being worked on.

Author Contributions: Conceptualization, M.B.; methodology, M.B.; formal analysis, M.B., C.B., and J.D.G.; writing-original draft, M.B., C.B. and J.D.G. All authors have read and agreed to the published version of the manuscript. 
Funding: This research was funded by Project PID2019-105601GB-I00/AEI/10.13039/501100011033 and Research Group FQM-126 (Junta de Andalucía).

Institutional Review Board Statement: Not applicable.

Informed Consent Statement: Not applicable.

Data Availability Statement: Not applicable.

Conflicts of Interest: The authors declare no conflict of interest.

\section{References}

1. Makar, K.; Bakker, A.; Ben-Zvi, D. The Reasoning Behind Informal Statistical Inference. Math. Think. Learn. 2011, 13, 152-173. [CrossRef]

2. Lugo-Armenta, J.G.; Pino-Fan, L.R. Inferential Reasoning of Secondary School Mathematics Teachers on the Chi-Square Statistic. Mathematics 2021, 9, 2416. [CrossRef]

3. Prodromou, T. Model-based Informal Inference. Int. J. Stat. Probab. 2017, 6, 140. [CrossRef]

4. OECD. PISA 2018 Assessment and Analytical Framework; OECD: Paris, France, 2019. [CrossRef]

5. Carraher, D.W.; Schliemann, A.L. Early algebra and algebraic reasoning. In Second Handbook of Research on Mathematics Teaching and Learning; Lester, F., Ed.; Information Age \& NCTM: Charlotte, NC, USA; Reston, VA, USA, 2007; Volume 2, pp. $669-705$.

6. Kaput, J. What is algebra? What is algebraic reasoning? In Algebra in the Early Grades; Kaput, J., Carraher, D.W., Blanton, M.L., Eds.; Routledge: London, UK, 2008; pp. 1-17.

7. Godino, J.D.; Aké, L.; Gonzato, M.; Wilhelmi, M.R. Niveles de algebrización de la actividad matemática escolar. Implicaciones para la formación de maestros. Enseñanza Cienc. 2014, 32, 199-219. [CrossRef]

8. Godino, J.D.; Neto, T.; Wilhelmi, M.R.; Aké, L.; Etchegaray, S.; Lasa, A. Niveles de algebrización de las prácticas matemáticas escolares. Articulación de las perspectivas ontosemiótica y antropológica. Av. Investig. Educ. 2015, 8, 117-142. [CrossRef]

9. Australian Curriculum, Assessment and Reporting Authority [ACARA]. Foundation to Year 10 Curriculum: Statistics and Probability (ACMSPO24). 2014. Available online: http://www.australiancurriculum.edu.au/mathematics/curriculum/f-10 ?layout=1 (accessed on 26 April 2021).

10. Ministerio de Educación, Cultura y Deporte. Real Decreto 126/2014, de 28 de Febrero, por el que se Establece el Currículo Básico de la Educación Primaria; MECD: Madrid, Spain, 2014.

11. Gal, I. Towards 'probability literacy' for all citizens. In Exploring Probability in School: Challenges for Teaching and Learning; Jones, G., Ed.; Springer: Berlin/Heidelberg, Germany, 2005; pp. 43-71.

12. Godino, J.D.; Batanero, C. Significado institucional y personal de los objetos matemáticos. Rech. Didact. Mathématiques 1994, 14, 325-355.

13. Godino, J.D.; Batanero, C.; Font, V. The onto-semiotic approach to research in mathematics education. ZDM 2007, $39,127-135$. [CrossRef]

14. Godino, J.D.; Batanero, C.; Font, V. The onto-semiotic approach: Implications for the prescriptive character of didactics. Learn. Math. 2019, 39, 37-42.

15. Batanero, C.; Henry, M.; Parzysz, B. The nature of chance and probability. In Exploring Probability in School; Jones, E.G., Ed.; Springer: Berlin/Heidelberg, Germany, 2005; pp. 15-37. [CrossRef]

16. Borovcnik, M.; Kapadia, R. A historical and philosophical perspective on probability. In Probabilistic Thinking; Chernoff, E., Sriraman, B., Eds.; Springer: Berlin/Heidelberg, Germany, 2014; pp. 7-34. [CrossRef]

17. Batanero, C.; Díaz, C. The meaning and understanding of mathematics. In Philosophical Dimensions in Mathematics Education; François, K., Ed.; Springer: Berlin/Heidelberg, Germany, 2007; pp. 107-127.

18. Bellhouse, D. De Vetula: A Medieval Manuscript Containing Probability Calculations. Int. Stat. Rev. 2000, 68, 123-136. [CrossRef]

19. Batanero, C. Significados de la probabilidad en la educación secundaria. Relime 2005, 8, 247-264.

20. Heitele, D. An epistemological view on fundamental stochastic ideas. Educ. Stud. Math. 1975, 6, 187-205. [CrossRef]

21. Godino, J.D. Un enfoque ontológico y semiótico de la cognición matemática. Rech. Didact. Math. 2002, 22, 237-284.

22. Godino, J.D.; Batanero, C.; Cañizares, M.J. Azar y Probabilidad. Fundamentos Didácticos y Propuestas Curriculares; Síntesis: Madrid, Spain, 1987.

23. Hernández-Solís, L.A.; Batanero, C.; Gea, M.M.; Álvarez-Arroyo, R. Comparación de probabilidades en urnas: Un estudio con estudiantes de Educación Primaria. Uniciencia 2020, 35, 1-19. [CrossRef]

24. Llinares, S. Fracciones, decimales y razón. Desde la relación parte-todo al razonamiento proporcional. In Didáctica de la Matemática para Primaria; Chamorro, M.C., Ed.; Pearson Prentice Hall: Hoboken, NJ, USA, 2003; pp. 187-220.

25. Drijvers, P. Learning Algebra in a Computer Algebra Environment: Design Research on the Understanding of the Concept of Parameter. Ph.D. Dissertation, University of Utrecht, Utrecht, The Netherlands, 2003.

26. Alcaide, F.; Sanz, L.; Hernández, J.; Moreno, M.; Serrano, E. Matemáticas Aplicadas a las Ciencias Sociales I; SM: Madrid, Spain, 2017.

27. Ministerio de Educación, Cultura y Deporte. Real Decreto 1105/2014, de 26 de Diciembre, por el que se Establece el Currículo Básico de la Educación Secundaria Obligatoria y del Bachillerato; MECD: Madrid, Spain, 2015. 
28. Langrall, C.W.; Mooney, E.S. Characteristics of elementary school students' probabilistic reasoning. In Exploring Probability in School; Jones, G., Ed.; Springer: New York, NY, USA, 2005; pp. 95-119.

29. Van Dooren, W. Probabilistic thinking: Analyses from a psychological perspective. In Probabilistic Thinking; Chernoff, E., Sriraman, B., Eds.; Springer: Berlin/Heidelberg, Germany, 2014; pp. 123-126.

30. Burgos, M.; Godino, J.D. Modelo ontosemiótico de referencia de la proporcionalidad. Implicaciones para la planificación curricular en primaria y secundaria. AIEM 2020, 18, 1-20. [CrossRef]

31. Fischbein, E. The Intuitive Sources of Probabilistic Thinking in Children; Reidel: Kufstein, Austria, 1975.

32. Fischbein, E. The interaction between the formal, the algorithmic and the intuitive components in a mathematical activity. In Didactics of Mathematics as a Scientific Discipline; Biehler, R., Scholz, R.W., Sträßer, R., Winkelmann, B., Eds.; Kluwer: Alphen aan den Rijn, The Netherlands, 1994; pp. 231-245.

33. Freudenthal, H. Revisiting Mathematics Education. China Lectures; Kluwer: Alphen aan den Rijn, The Netherlands, 1991.

34. Vásquez, C.; Alsina, Á.; Pincheira, N.; Gea, M.M.; Chandia, E. Construcción y validación de un instrumento de observación de clases de probabilidad. Enseñanza Cienc. 2020, 38, 25-43. [CrossRef] 